\title{
Effect of Integrated Ayurveda and Yoga Therapy (IAYT) on osteoporosis detected in breast cancer patient on remission- A single case study
}

\author{
Satyam Tripathi*, Megha Panchal, Nooraini Binti Aliyas
}

Union Yoga Ayurveda, Singapore

\section{KEY WORDS}

Osteoporosis

Breast Cancer

Yoga

Ayurveda

Meditation

Breathing

\section{*Corresponding Author:}

\section{Satyam Tripathi, MD}

Union Yoga Aurveda, Singapore

Contact no: +65832166170

E-mail: ayur.st@gmail.com

\begin{abstract}
This is a case study for invasive ductal carcinoma diagnosed in a patient aged 60 years in 2015 . She went through chemotherapy and radiotherapy and was on remission in 2016. Bone density degeneration was the side effect from the breast cancer treatment. After trying the conventional treatment, she was not satisfied, she came to Union Yoga Ayurveda (UYA), Singapore. She came to clinic looking for alternative therapy to help her increase her bone density, cope up with weakness and overall mental and physical wellbeing. The patient was given holistic treatment of yoga and Ayurveda, involving patra pinda sweda (herbal compress) and picchu (herbal soaked gauze pieces). The yoga therapy involved asanas practise to increase strength, breathing and meditation for overall wellbeing. The patient was not on any other treatment/medication during the entire treatment. After uninterrupted therapy for six months there was an increase in her bone density along with increase in energy level. The patient case study is an attempt to provide yoga and Ayurveda as an alternative/supportive treatment for remission management osteoporosis from breast cancer patients.
\end{abstract}

doi: 10.38205/imcr.010223

\section{Introduction}

Globally, around two million women are diagnosed with cancer and among the diagnosed, breast cancer being a major contributor and most common (1). A study conducted by the Hai-Rim Shu et al showed the breast cancer mortality among the western countries such as United Sates and UK are showing declining trends whereas among Asian women, the incidence is increasing in Singapore, being the highest as compared to others regions of the Asia (2). Treatment of breast cancer include mastectomy (3) which was used since early $19^{\text {th }}$ century, with advancement of technology and knowledge of breast cancer, treatments such as chemotherapy, aromatase inhibitors, are being used and are currently in use (3). Recent days, much more advanced techniques of targeted chemotherapy and radiation therapy are also being used for the treatment of breast cancer. (3) But with these heavy treatments of chemotherapy and hormonal therapy, there is a huge toll on the other organs of the patient receiving treatment especially post-menopausal women as the prevalence of breast cancer is highest in these population (4). Considering post-menopausal women whose Bone Mineral Density (BMD) is increased, receiving these treatments would lead to bone loss with increased risk of the fractures and leading to osteoporosis $(4,5)$.

The treatment of breast cancer, even though highly advanced, yet it leads to series of psychological and social despair among the survivors. Studies shows that majority of patients, experience treatment-related distress, fear of recurrence, anxiety, post-traumatic stress disorder (6). Cancer, as both disease and psychological distress needs to be recognised and addressed not only to increase life span but also Quality of Life (QOL) (7).

The anxiety and post-traumatic stress impact the patient's body in various ways such as psychological, neurological and immunological imbalances. Further studies have revealed that chronic stress alters the hypothalamic-pituitary-adrenal (HPA) axis, resulting in hypercortisolism or glucocorticoid resistance. This decreases the growth hormones significantly affecting bone loss, contributing to Osteoporosis (8). To treat the patients with osteoporosis in such cases, several drugs and injections such as alendronate, zoledronic acid and ibandronate (all these drugs belong to bisphosphonate group) are available which slows down the bone remodelling process but leads to side effects like back pain, musculoskeletal pain, headache, dizziness, palpitation and more (9). A patient who has recovered from cancer will not be able to tolerate such adverse side-effects and there would be decrease in the QOL top, alternative treatment therapies such as Complementary and Alternative Medicine (CAM), which has shown in creating positive approach towards combating cancer and managing adverse effects of conventional treatments needs to be tried among the patients (10).

Yoga as a complementary therapy has proved to be beneficial tool for survivors of cancer patient to help them cope 
with depression, fear, and anxiety to improve the QOL and has shown benefit with osteoporosis $(10,11)$. Yoga is also coeffective, safe with no adverse effects. A regular practise of asanas provides effect to the bones increasing the BMD. A few studies have even shown reversal of condition from osteoporosis to osteopenia with yoga $(11,12)$. The therapeutic benefit of yoga can help one to relax, slow down the breath and shift the focus from sympathetic to parasympathetic, relieving stress which is detrimental to bone development (13). Also, according to Ayurveda, osteoporosis is a condition developed due to excessive vata (dosha having properties of wind and air) and can be subdued with use of herbs. A clinical study suggests use of Guggulu herb in Ayurveda provide relief to joint pain, swelling and tenderness (14).

Considering the evidence and positive effects shown by CAM, we have used an Integrated Ayurveda and Yoga Therapy (IAYT) therapy for reducing stress as well as increasing BMD on a 60 year female patient with bone density degeneration due to chemotherapy and radio therapy treatment for her invasive ductal carcinoma diagnosed in 2015.

\section{Case presentation}

\section{Eligibility Criteria}

Patients discharged from hospital and have been physically and mentally fit for yoga and physical therapies. Patient was considered clinically fit from approved medical hospital to do physical intervention.

\section{Design}

Single-case pre-post data and long term follow up of six months. Patient aged in 60's diagnosed with invasive ductal carcinoma in 2015, underwent chemotherapy and Radiotherapy. Bone density degeneration was diagnosed at the recovery stage as the side effect of the treatment. She went for conventional treatment of chemotherapy and radiotherapy for osteoporosis which helped her with very unsatisfied minimal improvement. Patient was on calcium and glucose supplements.

Finally, in early 2018, she decided to look for complementary therapy. Patient came to the clinic with osteoarthritis condition and complaints of body ache, joint pain, giddiness, and weakness due to chemotherapy sessions. The IAYT intervention began in April of 2018 after screening and consultation by the doctor in Union Yoga Ayurveda (UAY) clinic, Singapore. Therapy was conducted twice a week and data was taken after six-month of uninterrupted therapy, showing improvement in T-score.

\section{Intervention}

The IAYT therapy was introduced to the patient in the form of Ayurveda herbs and oil, yoga asanas, breathing and meditation. After consultation with the Ayurveda doctor the patient started with therapy sessions. She came to the clinic for the sessions on regular basis for six months. The sessions were
Patient diagnosed with breast cancer

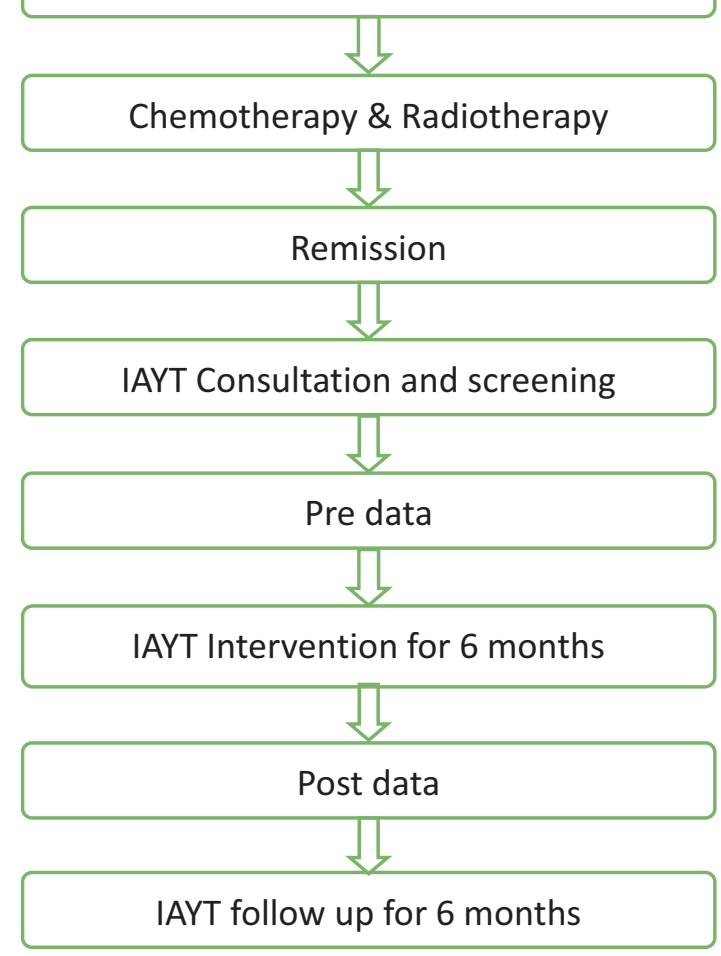

Fig. 1: Design of the Intervention.

conducted and administered by senior therapist. The intervention design is mentioned in the Figure 1.

Yoga and Ayurveda therapy sessions were held two times/week; 60-90 min each (Ayurveda therapy, yoga asanas, pranayama, meditation) by a specialist. Patient was made to lie down on the bed with complete relaxation and Ayurveda therapy of Picchu and Patra Pinda Sweda (PPS) were done. After Ayurveda session and few minutes of relaxation, yoga asanas were done as mentioned below (Table 1). A series of yoga asanas were done with deep and slow breathing, focusing on the hip and spine area. Considering the patient age and condition, all the asanas were done is slow pace using yoga strap and bolster for support and with proper guidance of breathing and focus more inwards. Pranic Energisation Technique (PET) and MSRT (Mind Sound Resonance Technique) was done as a part of meditation.

A feedback was taken after every fourth session and the patient was asked to mark the pain level using Visual Analogue Scale (VAS) and the results of pain level were analysed after 16 sessions.

Ayurveda therapy of Picchu is piece of cotton soaked in medicated oil and PPS, medicated herbs tied in a bolus were part of therapy at hip and spine $(15,16)$. PPS treatment helps to relieve pain, reduce swelling and stiffness of joints caused by osteoarthritis (17). A series of standing asanas were carried out to give positive stress to the bones. Seated, supine, prone asanas were more for creating opening and strength 
Table1: Integrated Approach of Yoga Therapy (IAYT) Module for Osteoporosis and Cancer

\begin{tabular}{|c|c|}
\hline Ayurveda therapy in hip and spine area - 40 mins & \\
\hline Picchu + Heat pack & 10 mins \\
\hline PPS (Patra Pinda Sweda) & 20 mins \\
\hline Yoga Asanas - 30 mins & \\
\hline Sukshmavyama & 10 mins \\
\hline Trikonasana & \multirow{8}{*}{20 mins } \\
\hline Vrikshasana & \\
\hline Ardhakati chakrasana & \\
\hline Pada hastasana & \\
\hline Viparita Karani & \\
\hline Ustrasana & \\
\hline Sasankasana & \\
\hline Bhujangasana & \\
\hline PET (Pranic Energisation Technique) & $30 \mathrm{mins}$ \\
\hline MSRT (Mind Sound Resonance Technique) & 15 mins \\
\hline
\end{tabular}

in spine area (as mentioned in Table 1). Several studies have shown positive effects of practising yoga asanas on improving the joint mobility, range of motion and flexibility of muscles and joints, thereby improving the BMD in osteoporotic condition (18). PET is a conscious movement of prana (vital energy) in the body which has shown considerable improvement in pain related to wounds, surgery, fracture (19) was performed. MSRT, a relaxation technique of yoga has been used to reduces stress, strengthen immune system, decrease pain, anxiety for patient suffering from Musculoskeletal issues (20) and to improve QOL (21).

\section{Assessment}

The assessment was done by measuring the BMD of the patient before and after therapy sessions. BMD measurement were conducted by an independent, nationally accredited lab in Singapore using Dual Energy X-ray Absorptiometry (DEXA) scan.

\section{Type of outcome}

Bone densitometry (T- score) by DEXA scan of-
a) Neck of femur
b) Hip bone and
c) Lumbar vertebrae.

DEXA is a low dose X-Ray scan to measure bone density to access and diagnose condition of osteoporosis. DEXA scan is also recognised by WHO as a gold standard to measure the BMD with most examined sites as hip and lower back area (22).

VAS is a method to measure chronic and acute pain. The reading of VAS taken after every fourth session was also a part of assessment. These reading were taken and recorded in an excel sheet and the results were analysed after at the end of $16^{\text {th }}$ session. It is usually represented as a $100 \mathrm{~mm}$ horizontal line to represent patient pain intensity by a point between extremes of "no pain" to "worst pain". It is the most simple, reliable and validated method to measure pain intensity or severity (23).

The result obtained after analysis of pre-post study are very encouraging. By six months of regular therapy, there have been significant improvements in all three parts of weight bearing bones. The lesser negative value of T-score shows improvement in bone density.

Lumbar vertebrae have increased density by $8.33 \%$, left hip became $15.38 \%$ more dense and femoral neck got the best improvement of $17.64 \%$ change (Table 2).

Table 2: Bone densitometry (T-score using Dual Energy X-ray Absorptiometry (DEXA) scan) of patient done before and after 6 months of Yoga and Ayurveda sessions

\begin{tabular}{|l|c|c|c|}
\hline Area BMD & $\begin{array}{c}\text { Pre therapy } \\
\text { (T-Score) }\end{array}$ & $\begin{array}{c}\text { Post therapy } \\
\text { (T-Score) }\end{array}$ & \% Change \\
\hline Lumbar & -2.4 & -2.2 & 8.33 \\
\hline Left Hip & -1.3 & -1.1 & 15.38 \\
\hline Femoral Neck & -1.7 & -1.4 & 17.64 \\
\hline
\end{tabular}

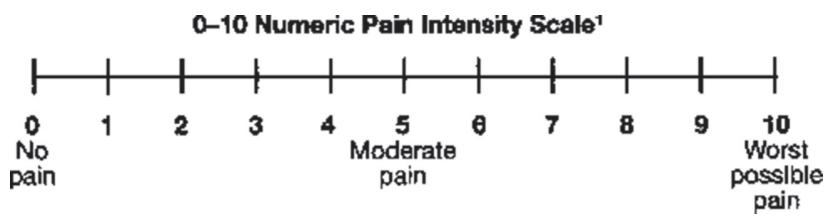

Fig. 2: Representing verbal numerical rating scale.

When the patient came to the clinic her intensity of pain was around seven on verbal numerical rating scale. (Figure 2) Sometimes pain lead to discomfort, resulting into disturbances in sleep cycle and felling of low energy and stiffness during the daytime, highly impacting her QOL. After having IAYT treatment for subsequent 16 weeks' time there was a gradual decrease in her intensity of pain around 36\%, which also helped her with better sleep cycle. With regular practise of yoga asanas, she felt better with her range of motion, her stiffness reduced by $27 \%$ and there was an encouraging increase in energy levels by $66 \%$, with reduction in her fatigue levels (Table 3 ).

Table 3: Patients pain measurement using VAS (Visual Analogue scale) measuring joint pain, stiffness, tiredness

\begin{tabular}{|l|c|c|c|}
\hline & Joint pain & Stiffness & Energy level \\
\hline Session 1 & 7 & 8 & 2 \\
\hline Session 8 & 6 & 6.5 & 4 \\
\hline Session 16 & 4.5 & 5 & 6 \\
\hline $\begin{array}{l}\text { Percentage (\%) } \\
\text { Improvement }\end{array}$ & $36 \%$ & $27 \%$ & $66 \%$ \\
\hline
\end{tabular}




\section{Discussion}

Yoga and Ayurveda has been used to complement against adverse effect of post chemotherapy conditions of cancer $(24,25)$. Chances of developing osteoporosis (4) is one of the common conditions for which calcium rich food, supplements along with medications like Raloxifene, Teriparatide, Denosumab and many more have been introduced for better recovery (9). Recovery needs a better support of complementary medicine and lifestyle change which can increase the absorption of calcium and can decrease the loss of electrolyte. With this clinical study we aimed to evaluate the effectiveness of an Ayurveda-Yoga medical treatment approach in osteoporosis seen as follow up condition during post cancer treatment. After 16 weeks Ayurveda-yoga integrative treatment led to a significantly greater and clinically relevant improvement of osteoporosis when corelated with complaints to pre-condition and instructions suggested by conventional guideline-based care with group differences maintained over few months.

This single case study is the first to evaluate the effectiveness of a complex multi-modal Ayurveda-yoga integrative medicine approach as a complementary medicine. It is a comparison of following only conventional medication with respect to adding complementary therapies with conventional medicine. The integrative treatment approach along with the conventional care were carefully designed with the aim of best practice for the patient with proper interim analysis by using VAS during treating the patient. The multi-modal integrative treatment was used as per studies which have been done for osteoarthritis and osteoporosis. Looking into the classical literature, its mentioned that Asthidhatu (bone tissue) is the fifth dhatu among seven dhatus. Nails \& hairs are mala (biproducts) of Asthidhatu. It is pitrajaghataka which troubles in this situation (26). The increase \& decrease of Asthi (bone) \& vata are related to each other in such a way that when vata increases Asthidhatu decreases \& vice versa (27). Hence the causative factor which increases of vata will cause decrease of Asthidhatu which further leads to Asthikshaya. In Asthikshaya there is pains, deformity in Kesha (hair), Nakha (nails), \& in Majjakshaya (Marrow depreciation) there is Asthisaushirya (bone dryness and weakness), timiradarshana (Giddiness) (28). With the therapy, the direction of action was against Asthidhatu kshaya or Asthikshaya condition. Herbs used for PPS (Warm bolus compress) were combinations which are relavant for Asthiposhana (nutrition) including Guggulu (Commiphora wightii), Aswagandha (Withania somnifera), Eranda leaf (Ricinus communis).

There have been studies which shows that Ayurveda therapies like PPS and pichu (herbal gauze piece) has been useful for arthritis condition (17). Studies have revealed that osteoporosis can also be taken care by using Ayurveda but working on cancer patients with post cancer therapies the recovery level as per $\mathrm{T}$ score and $\mathrm{Z}$ score at all level is remarkable. DEXA scan being a gold standard method of evaluation gives clearer picture that there have been physiological and structural changes which can be well reflected in this study.
Ayurveda therapy which includes heat and smoothening system of herb can be one of the causes of improved repair mechanism by increasing the blood flow carrying nutrition to the joints (29). Stress being one of the causative factors of loss of mineral in post chemotherapy condition can be very well managed by yoga (24). Yoga composition of relaxation techniques of mind body complex Ayurveda supplements and therapy increases the nutrition absorption in the body along with relaxation of muscle from tensed condition which can decrease cramps and discomfort (15). Yoga asanas are very safe, comfortable and helps in increasing the BMD in the spine and hip area (30). Relaxation of mind body complex by yoga Ayurveda affects the thyroid and metabolic function which allows the electrolyte to stay with bones and get bonded by the bone structure leading to higher bone density. The hypothalamicpituitary-adrenal (HPA) axis, thus without stress rearranges the altered system back into normal with appropriate cortisol level and less glucocorticoid resistance. Growth hormones which were contributing to osteoporosis (8) can be seen getting normalized. Ayurveda supplements as part of diet and application therapy and yoga as an instrument to work on neuroendocrine level has been the major key in many studies and same can be seen in this case (31).

Looking into all these studies and the results of VAS and DEXA gives us a vision to keep this case-report as an idol and can project for a bigger study in post cancer patients with osteoporosis.

\section{Conclusion}

This shows that IAYT as a complementary therapy can be added as a post treatment therapy for patient suffering from breast cancer and osteoporosis as underlying condition, which can significantly help building BMD as well as overall wellbeing. Further randomized controlled trials with bigger sample groups will be needed to clarify the mechanism of study and to evaluate the efficiency of the therapy.

\section{Acknowledgement}

This case study is made possible through the help and support from family, friends and all sentient beings. Our deep sense of gratitude to UYA Center for their active and passive support. We would like to extend our gratitude to Mr Vinod Bhatt for guiding in structuralizing the ethical work. Last but not the least we would want to extend our appreciation who could not be mentioned here but played their role to inspire us to complete this work.

\section{Author contribution}

Dr Satyam Tripathi as Principal Investigator for the case lead the work from its conception to completion together with diagnosis and prescription of treatment plan with dosage and duration of therapy along with intermediate reviews. Based on contemporary research in this area, Panchal Megha studied available body of knowledge around the treatment prescribed and compared results from yoga and Ayurveda 
therapy treatments. Panchal Megha is also instrumental in documenting the results and scripting the precis in this case study. Aliyas Nooraini skilled in yoga and Ayurveda therapy treatment, provided the patient with the detailed therapy and charted the observations. All authors discussed the results and contributed to the final manuscript.

\section{Source of funding}

Nil.

\section{Informed consent}

The informed consent was obtained from the patient.

\section{Conflict of interest}

The authors declare no conflict of interest.

Received Date: 10-11-19; Revised Date: 06-05-20

Accepted Date: $12-06-20$

\section{References}

1. Ginsburg O, Bray F, Coleman MP, Vanderpuye V, Eniu A, Kotha SR, et al. The global burden of women's cancer s: a grand challenge in global health. The Lancet. 2017;389(10071):847-60.

2. Shin H-R, Boniol M, Joubert C, Hery C, Haukka J, Autier P, et al. Secular trends in breast cancer mortality in five East Asian populations: Hong Kong, Japan, Korea, Singapore and Taiwan. Cancer Science. 2010; 101(5):1241-6.

3. Zurrida S, Veronesi U. Milestones in Breast Cancer Treatment. The Breast Journal. 2014;21(1):3-12.

4. Ramaswamy B, Shapiro CL. Osteopenia and osteoporosis in women with breast cancer. Seminars in Oncology. 2003;30(6):763-75.

5. Shah R. Pathogenesis, prevention, diagnosis and treatment of breast cancer. World Journal of Clinical Oncology. 2014;5(3):283.

6. Silva AVD, Zandonade E, Amorim MHC. Anxiety and coping in women with breast cancer in chemotherapy. Revista Latino-Americana de Enfermagem. 2017;25.

7. French-Rosas LN, Moye J, Naik AD. Improving the Recognition and Treatment of Cancer-Related Posttraumatic Stress Disorder. Journal of Psychiatric Practice. 2011;17(4):270-6.

8. Azuma K, Adachi Y, Hayashi H, Kubo K-Y. Chronic Psychological Stress as a Risk Factor of Osteoporosis. Journal of UOEH. 2015;37(4): 245-53.

9. Tu, KN, Lie JD, Wan CKV, Cameron M, Austel AG, Nguyen JK. Osteoporosis: A Review of Treatment Options. Pharmacy and Therapeutics. 2018;43(2):92-104.

10. Cramer H, Lauche R, Klose P, Lange S, Langhorst J, Dobos GJ. Yoga for improving health-related quality of life, mental health and cancerrelated symptoms in women diagnosed with breast cancer. Cochrane Database of Systematic Reviews. 2017.

11. Lu Y-H, Rosner B, Chang G, Fishman LM. Twelve-Minute Daily Yoga Regimen Reverses Osteoporotic Bone Loss. Topics in Geriatric Rehabilitation. 2016;32(2):81-7.

12. Fishman LM. Yoga for Osteoporosis. Topics in Geriatric Rehabilitation. 2009;25(3):244-50.
13. Woodyard C. Exploring the therapeutic effects of yoga and its ability to increase quality of life. International Journal of Yoga. 2011;4(2):49.

14. Dudhamal T, Sharma A, Gupta S, Mahanta V. Clinical study of Agnikarma and Panchatikta Guggulu in the management of Sandhivata (osteoartheritis of knee joint). AYU (An international quarterly journal of research in Ayurveda). 2016;37(1):38.

15. Bhusal N, Prakash S, Mangal G. REVIEW ONPATRA PINDA SWEDA: A PECULIARAYURVEDABOLUS FOMENTATION. International Ayurvedic Medical Journal. 2017;5.

16. Mishra L, Singh B, Dagenais S. Healthcare and disease management in Ayurveda. Alternative Therapies in Health and Medicine. 2001;7(2): 44-50.

17. Dave A, Joshi A, Mehta C, Shukla V. Clinical effect of Nirgundi Patra pinda sweda and Ashwagandhadi Guggulu Yoga in the management of Sandhigata Vata (Osteoarthritis). AYU (An International Quarterly Journal of Research in Ayurveda). 2011;32(2):207.

18. Bedekar N, Motorwala Z, Kolke S, Panchal P, Sancheti P, Shyam A. Effects of Yogasanas on osteoporosis in postmenopausal women. International Journal of Yoga. 2016;9(1):44.

19. Oswal P, Nagarathna R, Ebnezar J, Nagendra HR. The Effect of Add-On Yogic Prana Energization Technique (YPET) on Healing of Fresh Fractures: A Randomized Control Study. The Journal of Alternative and Complementary Medicine. 2011;17(3):253-8.

20. Sharma D, Bhargav H. Effect of Mind Sound Resonance Technique as an add on to Yoga therapy on Quality of sleep, Pain, Stress and State Anxiety levels in patients suffering from Chronic Musculoskeletal Pain: Matched Controlled Trial. Int. J. Rev. Life. Sci. 2014;4(2):27-31.

21. Metri K. Effects of Mind Sound Resonance Technique (Yogic relaxation) on Psychological States, Sleep Quality, and Cognitive Functions in Female Teachers: A Randomized, Controlled Trial. Advances in mind-body medicine. 2017;31(1):4-9.

22. Anwar F, Iftekhar H, Taher T, Kazmi SK, Rehman FZ, Humayun M, et al. Dual Energy X-ray Absorptiometry Scanning and Bone Health: The Pressing Need to Raise Awareness Amongst Pakistani Women. Cureus. 2019.

23. Delgado DA, Lambert BS, Boutris N, Mcculloch PC, Robbins AB, Moreno MR, et al. Validation of Digital Visual Analog Scale Pain Scoring With a Traditional Paper-based Visual Analog Scale in Adults. JAAOS: Global Research and Reviews. 2018;2(3).

24. Sisk A, Fonteyn M. Evidence-Based Yoga Interventions for Patients With Cancer. Clinical Journal of Oncology Nursing. 2016;20(2):181-6.

25. Galantino ML, Greene L, Daniels L, Dooley B, Muscatello L, O'donnell L. Longitudinal Impact of Yoga on Chemotherapy-Related Cognitive Impairment and Quality of Life in Women with Early Stage Breast Cancer: A Case Series. Explore. 2012;8(2):127-35.

26. Shastri A. Sushruta Samhita of Sushruta, Sharira Sthana 12th ed. Varanasi: Chaukhambha Sanskrit Bhawan; 1993

27. Gadre G, Prakashana R. Asthang Hridaya Sutra sthana Volume eleven. $12^{\text {th }}$ edition. Varanasi: Chaukhambha Sanskrit Bhawan; 1996.

28. Gadre G, Prakashana R. AsthangHridaya, Sutra sthana. Volume twelve. $12^{\text {th }}$ edition. Varanasi: Chaukhambha Sanskrit Bhawan; 1996

29. Sharma M, Mehta C, Shukla D, Patel K, Patel M, Gupta S. Multimodal Ayurvedic management for Sandhigatavata (Osteoarthritis of knee joints). AYU (An International Quarterly Journal of Research in Ayurveda). 2013;34(1):49.

30. Lu Y-H, Rosner B, Chang G, Fishman LM. Twelve-Minute Daily Yoga Regimen Reverses Osteoporotic Bone Loss. Topics in Geriatric Rehabilitation. 2016;32(2):81-7.

31. Mahajan A. Role of yoga in hormonal homeostasis. International Journal of Clinical and Experimental Physiology. 2014;1(3):173. 